\title{
MUNICIPAL ASSESSMENTS VERSUS ACTUAL SALES PRICES IN HEDONIC PRICE STUDIES
}

\author{
Mario du Preez* \\ Nelson Mandela Metropolitan University \\ mario.dupreez@nmmu.ac.za
}

Received: Janaury 2014

\author{
Michael Sale \\ Nelson Mandela Metropolitan University \\ michael.sale@nmmu.ac.za
}

Accepted: November 2014

\begin{abstract}
In most hedonic price model studies, the actual sales price of a property is employed as the dependent variable in the parametric regression analysis. Although the use of this price is pervasive, alternatives to it do exist. One such alternative is the assessed property value, which is more readily available than the actual property price. The aim of this study is to compare implicit price estimates of property characteristics (both structural and locational) based on actual sales price data and assessed property values. To this end, a seemingly unrelated regression with two hedonic price equations is used, one which employs actual market prices as the dependent variable and the other which employs assessed values. The results show that the hypothesised influence of structural and locational housing characteristics on residential property prices is the same for assessed values, and actual market prices cannot be accepted. This finding should act as a caution for hedonic practitioners not to base their conclusions and recommendations solely on the use of assessed values in hedonic price models.
\end{abstract}

Keywords

Municipal assessment, sales price, hedonic pricing, house characteristics, residential property

*Prof $\mathbf{M}$ du Preez is a professor in the Department of Economics, Nelson Mandela Metropolitan University, Port Elizabeth, South Africa.

\#Dr M Sale is a lecturer in the Department of Economics, Nelson Mandela Metropolitan University, Port Elizabeth, South Africa. 


\section{INTRODUCTION}

The hedonic price model is generally used to estimate the effects of non-market amenities and disamenities on adjacent property values (Rosen, 1974). The source of data on housing prices is an important theoretical consideration to take into account when deciding on the appropriate dependent variable to use for a hedonic price analysis, with data on actual market transactions being preferable (Kiel \& Zabel, 1999; Cotteleer \& Van Kooten, 2012; Ma \& Swinton, 2012). Although actual property prices are preferred (as they reflect how people allocate their money and, therefore, how they value property characteristics), assessed value estimates are often more readily available and have frequently been used as a substitute for actual property prices (Darling, 1973; Doss \& Taff, 1996; Lee, Taylor \& Hong, 2008). However, hedonic practitioners need to be cautioned that a dependent variable other than the actual sales price (i.e. an assessed property value) may be imperfectly correlated with actual market prices (Freeman, 2003). If this is the case, the errors in measuring the assessed value of the structure will conceal the underlying relationships between the property values and house characteristics (i.e. biased coefficient estimates will be present in the model) (Freeman, 2003).

Although preferred, the use of actual sales prices is also not immune to disadvantages, with the main disadvantage being a potential lack of data if sales do not occur frequently (Cotteleer \& Van Kooten, 2012). In addition to this, the threat of errors in sales price data is also present, along with the risk of distorted markets (Doss \& Taff, 1996). Distorted markets occur as a result of asymmetric information and tend to be common in markets where real estate agents and lenders are dominant in the market (Doss \& Taff, 1996). Real estate agents may influence the market by affecting the list price of properties and by affecting the bidding strategies of buyers. Lenders may affect the market with their lending practices (for example, by requesting large deposits from first time buyers) (Doss \& Taff, 1996). Other transactions, such as trading between relatives, may not reflect true market values either. For this reason, it is recommended that all transactions that are not of arm's-length should be excluded from the hedonic analysis (Cotteleer \& Van Kooten, 2012).

Previous studies have attempted to compare coefficient estimates for property characteristics using regression equations with different dependent variables (Nicholls \& Crompton, 2007; Bowman, Thompson \& Colletti, 2009). These studies, however, did not develop test statistics in order to compare these estimates. Only one study could be found in the international literature that developed test statistics for this comparison - the study by Cotteleer and Van Kooten (2012).

In line with the methodology followed by Cotteleer and Van Kooten (2012), the contribution of this paper is to provide a complete analysis and statistically test for differences in parameter estimates obtained from assessed values versus actual sales prices. To achieve this, a seemingly unrelated regression (SUR) hedonic price model consisting of two equations was estimated one with municipal assessed values as the dependent variable and the other employing actual sales prices as the dependent variable. The resulting parameter estimates were then compared.

The remainder of the paper is organised as follows: section 2 presents the methodology of the SUR. Section 3 presents the data and variables used in the study. Section 4 presents the empirical results of the SUR and investigates the statistical differences present in the two equations. Section 5 concludes the paper. 


\section{METHODOLOGY}

In order to test for statistical differences between assessed values and sales prices, the correlation coefficient between the assessed values and the actual sales prices was calculated. Histograms for the distribution of actual sales prices and assessed values were also constructed and a paired $t$-test was performed. In addition to this, a SUR model was estimated to test for significant differences between the two equations. The correlation coefficient, $r$, is a measure of the strength of the linear relationship between two variables (Studenmund, 2006). This is defined as:

$$
r=\operatorname{cov}(X, Y) / S_{x} S_{y}
$$

where: $\quad c o v=$ sample covariance

$S_{X}=$ sample standard deviation of variable $X$

$S_{y}=$ sample standard deviation of variable $Y$

The correlation coefficient will always lie between -1 and 1 (Keller, 2011). A value of -1 indicates a perfect negative relationship, a value of 0 indicates no relationship and a value of 1 indicates a perfect positive relationship (Keller, 2011). A paired $t$-test is used to determine whether or not there is a significant difference in two population means. In order to conduct a paired $t$-test, it is necessary to pair the observations in one of the samples with the observations in the other (Shier, 2004). The relevant $t$-statistic is calculated as follows:

$$
t=\bar{d} / S E(\bar{d})
$$

where: $\quad \bar{d}=$ the mean difference

$S E=$ the standard error of the mean difference

The $t$-statistic is then used to test the null hypothesis that no significant difference in the mean values is present (Shier, 2004).

A SUR model involves pairing the actual sales prices and assessed values and specifying a regression model for each of the properties for which both values are available (Cotteleer \& Van Kooten, 2012). By analysing both equations in one model, the relevant test statistic can be derived (i.e. the Wald statistic).

Generally, the SUR model specifies the $m^{\text {th }}$ of Mequations for the $t^{\text {th }}$ of $N$ individuals as follows:

$$
P_{i m}=x_{i m}^{\prime} \beta_{m}+\varepsilon_{i m}, m=1, \ldots, M, i=1, \ldots, N,
$$

where: $\quad x_{i m}=$ regressors that are assumed to be exogenous

$$
\begin{aligned}
& \beta_{m}=K_{m} \times 1 \text { parameter vectors } \\
& \varepsilon_{m}=\text { an error term }
\end{aligned}
$$

$P_{m}$ could, for example, represent the $t^{\text {th }}$ individual's expenditure on house $m$ and $x_{i m}$ could, for example, represent a matrix of house characteristics. In order to estimate the SUR model, observations over both equations and individuals are combined (Cameron \& Trivedi, 2005). If independence over $i$ is assumed, all equations for a given individual are first stacked (Cameron \& Trivedi, 2005). 
The process of stacking Mequations for the $t^{\text {th }}$ individual produces the following:

$$
\left[\begin{array}{c}
P_{i 1} \\
\vdots \\
P_{i M}
\end{array}\right]=\left[\begin{array}{ccc}
x^{\prime}{ }_{i 1} & 0 & 0 \\
0 & \ddots & 0 \\
0 & 0 & x^{\prime}{ }_{i m}
\end{array}\right]\left[\begin{array}{c}
\beta_{1} \\
\vdots \\
\beta_{M}
\end{array}\right]\left[\begin{array}{c}
\varepsilon_{i 1} \\
+ \\
\varepsilon_{i M}
\end{array}\right]
$$

which represents the following form:

$$
P_{i}=X_{i} \beta+\varepsilon_{i}
$$

where: $\quad P_{i}$ and $\varepsilon_{1}=M \times 1$ vectors with $m^{\text {th }}$ entries $P_{i m}$ and $\varepsilon_{i m}$

$$
X_{\mathrm{i}} \quad=M \times K \text { matrix with } m^{\text {th }} \text { row }\left[0 \ldots \mathrm{x}^{\prime}{ }_{i m} \ldots 0\right]
$$

$\beta=\left[\beta_{1}^{\prime}{ }_{1} \ldots \beta_{M}^{\prime}\right]^{\prime}=K \times 1$ vector where $K=K_{1}+\ldots K_{M}$.

Given the definitions of $X_{i}$ and $P_{i}$ it can be shown that $\hat{\beta}_{\text {sols }}$ is:

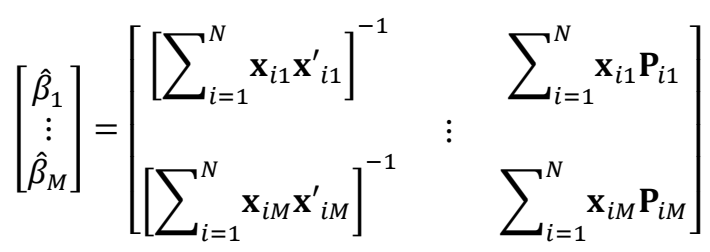

which implies that system OLS (SOLS) is identical to separate equation-by-equation OLS (Cameron \& Trivedi, 2005). In cases where all Mequations have the same regressors, the efficient estimator is single equation OLS (Greene, 2011). Alternative estimators include the feasible generalised least squares (GLS) estimator and the maximum likelihood estimator (Cameron \& Trivedi, 2005). In many cases the feasible GLS estimator is more efficient compared to systems OLS but it collapses to OLS if precisely the same regressors are present in each equation.

Once the SUR model has been estimated, the Wald statistic can be calculated to test whether the restriction $\beta_{1}=\beta_{2}$ holds (i.e. the Wald statistic tests the hypothesis that coefficients in the equation with actual market prices as the dependent variable are equal to the coefficients in the equation with assessed values as the dependent variable (Cotteleer \& Van Kooten, 2012)). More formally,

$$
\begin{aligned}
& \mathrm{H}_{0}: \beta_{1}=\beta_{2} \\
& \mathrm{H}_{\mathrm{a}}: \beta_{1} \neq \beta_{2}
\end{aligned}
$$

where: $\quad \beta_{1}=$ the estimated coefficients for the actual sales prices equation

$\beta_{2}=$ the estimated coefficients for the assessed values equation

\section{DATA AND VARIABLES}

The locus of this study is the neighbourhood of Walmer, situated in Port Elizabeth, Nelson Mandela Bay, Eastern Cape. The upmarket Walmer neighbourhood is situated approximately 10 minutes by vehicle from Port Elizabeth's main beaches. The suburb is home to longstanding Port 
Elizabeth families and its history dates back to the early 1800s. Various amenities are located in close proximity to it. The area is well catered for in terms of residential property. Free-standing homes, townhouse complexes, security complexes and guesthouses can be found in the area. FIGURE 1 shows a map of the Walmer Neighbourhood.

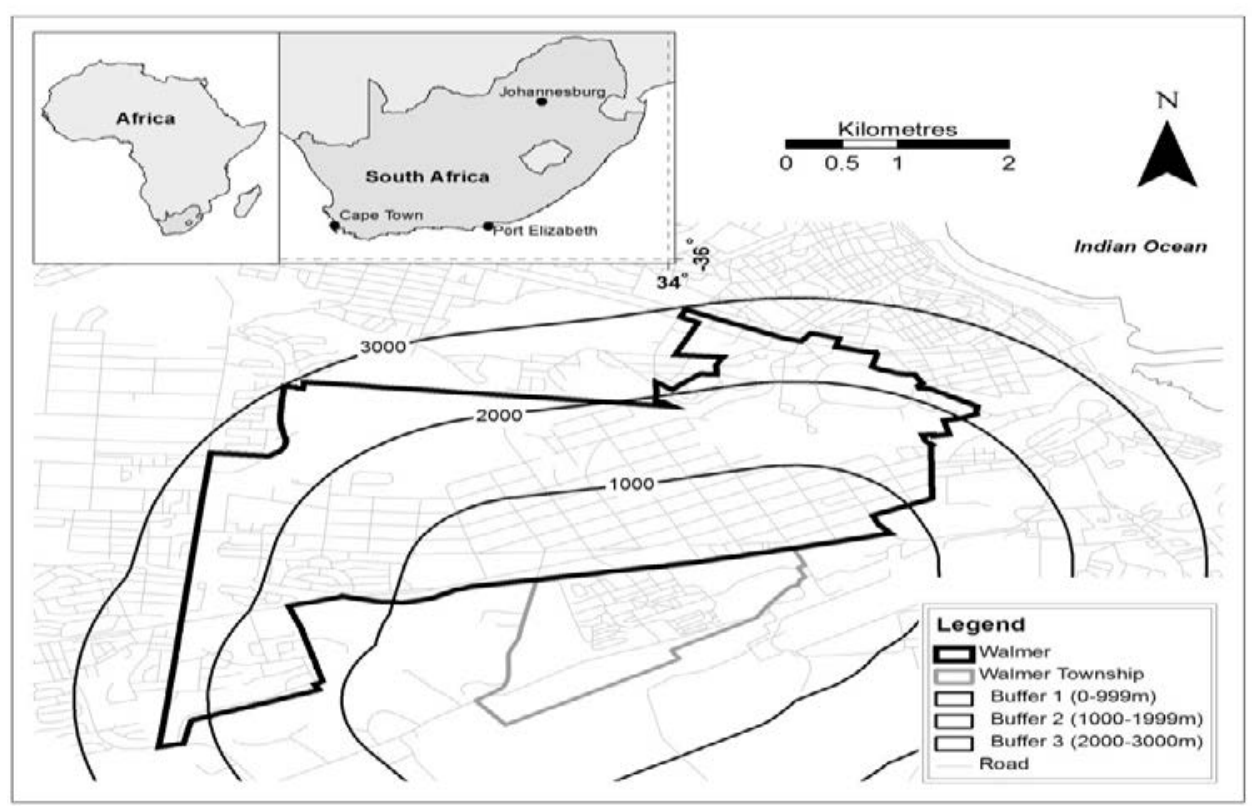

FIGURE 1: The geographical location of the Walmer neighbourhood and the Walmer Township

The Walmer neighbourhood has a total of 2625 residential properties, and a total of 1326 transactions took place from 1995 to 2009 (excluding repeat sales) (South African Property Transfer Guide, 2011). The population in this study was, thus, limited to the 1326 transactions that took place over the study period. Of these transactions, a simple random sample of 170 was drawn. The sample size was determined by employing the following equation:

$$
n=N /\left(1+N e^{2}\right)
$$

where:

$$
\begin{aligned}
& n=\text { sample size } \\
& N=\text { population size } \\
& e=\text { level of precision }
\end{aligned}
$$

Using Equation 7, the sample size was determined with a level of precision of $7.2 \%$, which ensured a representative sample from the population, because the generally accepted level of precision for representative samples is $10 \%$ or less (Fink, 2003).

Data on the 2007/2008 assessed values of properties (the specific valuation roll considered in this study) was purchased from the Nelson Mandela Bay Municipality, with the valuations applicable in this study becoming effective (for property rates purposes) on 1 July 2008. For the purposes of the 2007/2008 valuation the Nelson Mandela Bay Municipality outsourced the valuation task, which was awarded to a private-owned contractor, namely eValuations (Weyers, 2011). Historical sales price data for residential property stands in the neighbourhood of Walmer, Nelson Mandela Bay, that were traded at least once during the period 1995 to 2009 was 
also obtained. This data was purchased from the South African Property Transfers Guide (SAPTG). All transactions that were not arm's-length ones were excluded from the analysis. Data from the ABSA house price index (Port Elizabeth and Uitenhage) was then used to adjust assessed values and house prices to 2009 constant rands to control for real estate market fluctuations. Adjusting actual sales prices to control for house price inflation is a relatively common approach when the data originates from different years (Cummings \& Landis, 1993; Carroll \& Clauretie, 1999; Leggett \& Bockstael, 2000; Cho, Bowker \& Park, 2006; Cotteleer \& Van Kooten, 2012).

The selection of appropriate structural and neighbourhood characteristics was guided by a study by Sirmans, MacPherson and Zietz (2005). A total of 11 independent variables were thought to influence house prices in the Walmer neighbourhood, namely the number of bedrooms, the presence of a garage, the presence of air-conditioning, the number of bathrooms, the age of the house, the size of the erf, the number of storeys, the presence of an electric fence, the presence of a swimming pool, the distance to the Walmer Township and the distance to the nearest school. A lack of house characteristic data on the municipal database necessitated the physical collection of data. Information on the structural characteristics of houses in the Walmer neighbourhood was collected via personal interviews during January 2010. TABLE 1 presents the descriptive statistics of the dependent and independent covariates employed in the study.

TABLE 1: Descriptive statistics of the dependent and independent covariates used in the estimations $(n=170)$

\begin{tabular}{lcccc}
\hline Variable & Min & Max & Mean & Standard deviation \\
\hline Sales_price & 193600 & 4926800 & 1626395 & 774758 \\
Assessed_value & 500500 & 3976700 & 1784135 & 600255 \\
\hline Structural characteristics & & & & \\
\hline Bed & 2 & 8 & 3.6 & 0.91 \\
Garage & 0 & 1 & 0.81 & 0.40 \\
Aircon & 0 & 1 & 0.25 & 0.46 \\
Bath & 1 & 7 & 2.67 & 1.09 \\
Age & 1 & 80 & 55.45 & 21.85 \\
Erf_size & 380 & 4600 & 1776 & 629 \\
Storeys & 1 & 2 & 1.18 & 0.39 \\
Swim & 0 & 1 & 0.8 & 0.401 \\
Elec_fence & 0 & 1 & 0.26 & 0.44 \\
\hline Neighbourhood characteristics & & & & 1799 \\
\hline Dist_wal & 500 & 3200 & 1469 & 679 \\
Dist_school & 140 & 3200 & & 599 \\
\hline Surce:Authors calcutations & & & & \\
\hline
\end{tabular}

Source: Authors' calculations 
The average house in the sample has 3.6 bedrooms, 2.67 bathrooms, is 55.45 years old, has an erf size of 1776 square metres, has 1.18 storeys, and is located 1469 metres from the nearest school and 1799 metres from the Walmer Township. The majority of houses in the sample have a garage and a swimming pool, although less than half of the houses have air-conditioning or electric fencing. The average sales price is Rl 626395 and the average assessed value is Rl 784135 . As can be seen from TABLE 1 , assessed values appear to overvalue prices at the low end of the price spectrum, and undervalue prices at the top end. Unfortunately, a more thorough critical assessment of the municipal assessment model is not possible, since the assessment is outsourced to a privately owned contractor who is under no obligation to release the details of its operation.

\section{EMPIRICAL RESULTS}

It was first considered whether or not there were any significant differences between actual sales prices and assessed values. The correlation coefficient for the 170 observations was 0.79 , indicating an imperfect overlap. Actual sales prices are generally lower than assessed values, although actual sales prices have a larger standard deviation (see TABLE 1). This is also apparent from Figures 2 and 3.

As can be seen from Figures 2 and 3, the distribution of the assessed values has fewer observations in the tails of the distribution compared to actual sales prices. A paired $t$-test was also conducted in order to determine whether or not a significant difference between the mean values was present. The $t$-statistic of 2.1 was greater than the critical value of 1.96 . This led to the rejection of the null hypothesis of no significant difference between the two mean values. Although there is evidence of divergence between actual sales prices and assessed values, hedonic price models based on assessed values and actual sales values can still result in similar coefficient estimates of location-specific amenities (Cotteleer \& Van Kooten, 2012). Therefore, in order to compare the coefficient estimates derived using actual sales prices as the dependent variable with those using assessed values as the dependent variable a SUR model was estimated.

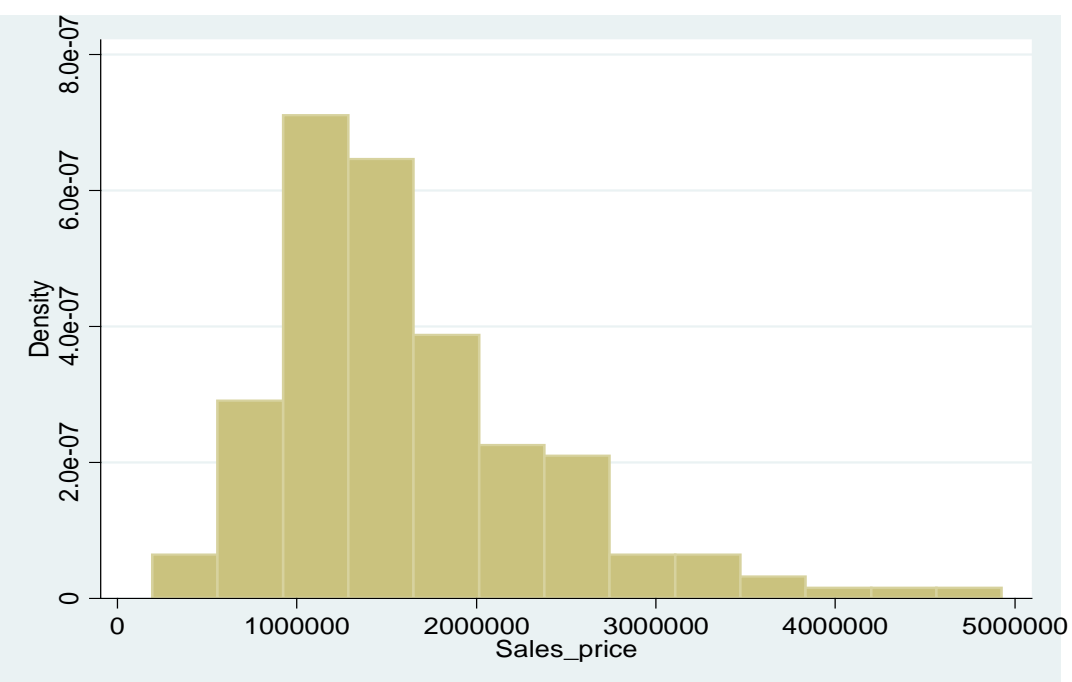

FIGURE 2: Actual sales price distribution 


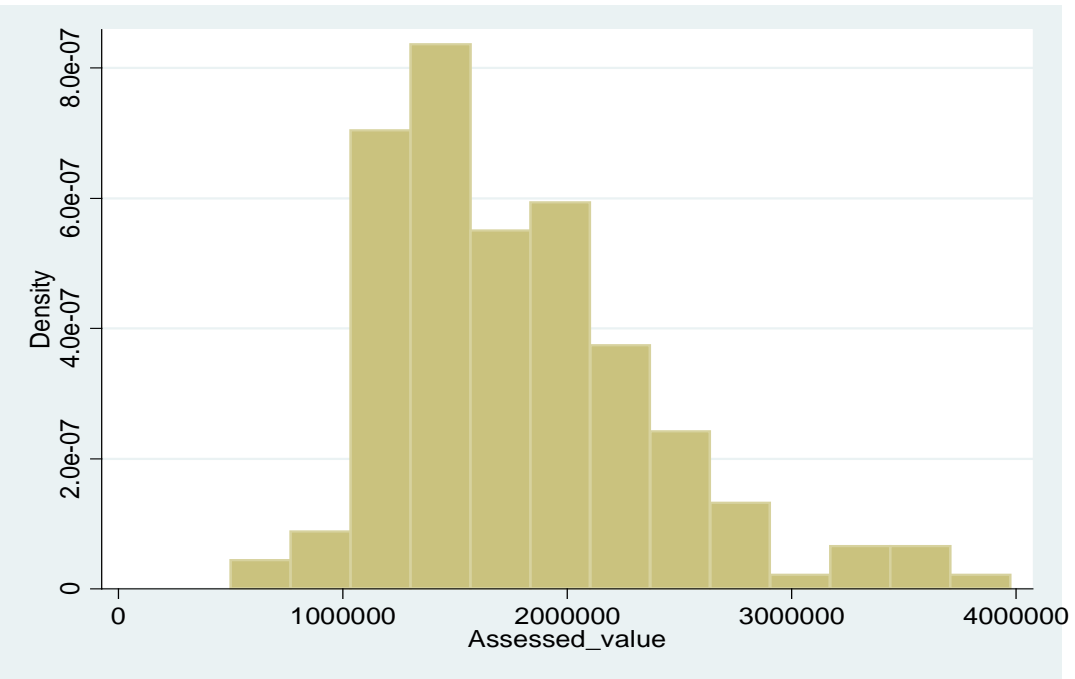

\section{FIGURE 3: Assessed value distribution}

TABLE 2 presents the results of the SUR. In the estimation of the SUR model, $m=1$ represented the equation with sales prices as the dependent variable and $m=2$ represented the equation with assessed values as the dependent variable (see Equation 3 ). Three model specifications were estimated, namely the linear, semi-log, and double-log. This allows for goodness-of-fit comparisons based on R-squared values. All models were estimated using Stata Version 11.0.

\section{TABLE 2: Estimation results for the SUR (standard errors in parentheses ${ }^{1}$ )}

\begin{tabular}{|c|c|c|c|c|c|c|}
\hline \multirow[b]{4}{*}{ Variable } & \multicolumn{6}{|c|}{ Model } \\
\hline & \multicolumn{2}{|c|}{ Linear } & \multicolumn{2}{|c|}{ Semi-log } & \multicolumn{2}{|c|}{ Double-log } \\
\hline & \multicolumn{2}{|c|}{ Dependent variable } & \multicolumn{2}{|c|}{ Dependent variable } & \multicolumn{2}{|c|}{ Dependent variable } \\
\hline & Sales_price & Assessed_value & Sales_price & $\begin{array}{c}\text { Assessed } \\
\text { value }\end{array}$ & Sales_price & $\begin{array}{c}\text { Assessed } \\
\text { value }\end{array}$ \\
\hline \multirow[t]{2}{*}{ Constant } & -740535.3 & -87872.14 & 12.76 & 13.45 & 9.57 & 11.2 \\
\hline & $(278355)$ & (201522) & $(0.174)$ & $(0.118)$ & $(0.73)$ & $(0.52)$ \\
\hline \multicolumn{7}{|c|}{ Structural characteristics } \\
\hline \multirow[t]{2}{*}{ Erf_size } & 580.57 & 535.96 & 0.0003 & 0.00027 & 0.299 & 0.23 \\
\hline & $(75.76)$ & (55) & $(0.00005)$ & $(0.00003)$ & $(0.06)$ & $(0.043)$ \\
\hline \multirow[t]{2}{*}{ Age } & 876.43 & 1839.15 & -0.0004 & 0.00077 & -0.0005 & 0.0006 \\
\hline & (2 067.4) & (1 497) & $(0.0013)$ & $(0.0009)$ & $(0.0013)$ & $(0.00097)$ \\
\hline \multirow[t]{2}{*}{ Storeys } & 278600.5 & 236269.1 & 0.17 & 0.119 & 0.156 & 0.109 \\
\hline & (118 212) & $(85582)$ & $(0.74)$ & $(0.05)$ & $(0.077)$ & $(0.055)$ \\
\hline \multirow[t]{2}{*}{ Bath } & 61209.5 & 70848.12 & 0.046 & 0.036 & 0.053 & 0.05 \\
\hline & $(47838)$ & (34 633) & $(0.03)$ & $(0.02)$ & $(0.31)$ & $(0.022)$ \\
\hline
\end{tabular}




\begin{tabular}{|c|c|c|c|c|c|c|}
\hline \multirow[b]{4}{*}{ Variable } & \multicolumn{6}{|c|}{ Model } \\
\hline & \multirow{2}{*}{\multicolumn{2}{|c|}{$\begin{array}{l}\text { Linear } \\
\text { Dependent variable }\end{array}$}} & \multicolumn{2}{|c|}{ Semi-log } & \multicolumn{2}{|c|}{ Double-log } \\
\hline & & & Depende & variable & Dependen & variable \\
\hline & Sales_price & Assessed_value & Sales_price & $\begin{array}{c}\text { Assessed } \\
\text { value }\end{array}$ & Sales_price & $\begin{array}{c}\text { Assessed } \\
\text { value }\end{array}$ \\
\hline \multirow[t]{2}{*}{ Bed } & -315 & -23524.19 & 0.024 & -0.008 & 0.048 & 0.015 \\
\hline & $(60340)$ & $(43684)$ & $(0.038)$ & $(0.026)$ & $(0.039)$ & $(0.028)$ \\
\hline \multirow[t]{2}{*}{ Swim } & 364337.9 & 84038.74 & 0.308 & 0.06 & 0.343 & 0.09 \\
\hline & $(116401)$ & $(84271)$ & $(0.073)$ & $(0.05)$ & $(0.75)$ & $(0.054)$ \\
\hline \multirow[t]{2}{*}{ Aircon } & 6010.76 & $131321.2 \ldots$ & 0.002 & 0.091 & 0.01 & 0.097 \\
\hline & $(97060)$ & $(70268)$ & $(0.06)$ & $(0.041)$ & $(0.063)$ & $(0.045)$ \\
\hline \multirow[t]{2}{*}{ Garage } & 41360.15 & 54500.07 & -0.007 & 0.05 & 0.0033 & 0.07 \\
\hline & $(41360)$ & $(84198)$ & $(0.073)$ & $(0.05)$ & $(0.075)$ & $(0.054)$ \\
\hline \multirow[t]{2}{*}{ Elec_fence } & 279153.4 & 227486.3 & 0.14 & 0.13 & 0.156 & 0.133 \\
\hline & (279 153) & $(72751)$ & $(0.63)$ & $(0.043)$ & $(0.066)$ & $(0.047)$ \\
\hline \multicolumn{7}{|c|}{ Neighbourhood characteristics } \\
\hline \multirow[t]{2}{*}{ Dist_Wal } & 198 & 178.82 & 0.00013 & 0.0000953 & 0.2 & 0.15 \\
\hline & (84) & $(61)$ & $(0.00005)$ & $(0.0000357)$ & $(0.078)$ & $(0.056)$ \\
\hline \multirow[t]{2}{*}{ Dist_school } & 25.59 & -61.48 & 0.000002 & -0.00004 & 0.016 & -0.025 \\
\hline & $(75)$ & (54) & $(0.00005)$ & $(0.000032)$ & $(0.052)$ & $(0.037)$ \\
\hline R-squared & 0.48 & 0.54 & 0.48 & 0.51 & 0.44 & 0.41 \\
\hline
\end{tabular}

Source: Authors' calculations

* Significant at the $1 \%$ level $\quad$ ** Significant at the $5 \%$ level $\quad$ *** Significant at the $10 \%$ level

${ }^{1}$ It is not possible to estimate robust standard errors in Stata (Damore \& Nicholson, 2014). However, when the two hedonic price equations were estimated independently using robust standard errors the results were unaffected.

A visual inspection of the coefficient estimates in the SUR model indicates that all the coefficients had similar signs in the actual sales price and assessed value equations, except for distance to the nearest school in all three of the models, age, number of bedrooms and presence of a garage in the semi-log model and age in the double-log model.

The coefficients of the number of bedrooms and the age variables are counterintuitive in the linear model. However, the international literature reveals that it is possible for hedonic price regressions to reveal counterintuitive signs on the coefficients of structural house characteristics (Sirmans et al., 2005). More specifically, a review of 78 hedonic price studies by Sirmans et al (2005) revealed that the coefficient on the age variable was positive seven times. The same review found that the number of bedrooms coefficient was negative in nine out of 40 cases (Sirmans et al., 2005). Overall, the models explained variation in actual sales price and assessed value fairly well, with $\mathrm{R}$-squared values ranging from $0.4 \mathrm{l}$ to 0.54 . Based on the results of the SUR model, the hypothesis that all 11 coefficients included in the linear model (excluding the constant) are equal was rejected with near certainty. More specifically, the Wald statistic 
was 119. This was greater than the Chi-squared critical value of 19.68 (with 11 degrees of freedom). The hypothesis that all 11 coefficients are equal in the semi-log model was also rejected with near certainty (the Wald statistic was 118.5). Finally, the Wald statistic of 88 generated by the double-log model indicates that the coefficients in this model are also significantly different.

These results are similar to the results obtained in the Cotteleer and Van Kooten (2012) study. In the Cotteleer and Van Kooten (2012) study the coefficient estimates of 29 house characteristics were too dissimilar to assume that they were equal in both equations.

The majority of the property characteristics included in the estimated SUR model displays the correct signs, with the exception of the age (age of the house) variable (positive sign) and the number of bedrooms (negative sign). A possible explanation for the negative sign on the age coefficient in both equations is the fact that the Walmer neighbourhood is one of Nelson Mandela Bay's oldest and most affluent suburbs. Buyers perhaps prefer the older, more traditional homes in the suburb. The other perplexing finding is the negative sign on the bed (number of bedrooms) coefficient. One would expect house prices and assessed values to be positively related to the number of bedrooms. The results of this study show the opposite. Perhaps more value is placed on the size of the bedrooms as opposed to the number.

The influence of the other variables on house prices and assessed values is fairly predictable. Properties situated on bigger erfs are valued more highly than properties situated on smaller erfs. The numbers of storeys, number of bathrooms, the presence of a swimming pool, the presence of an air-conditioner, the presence of a garage and the presence of an electric fence all have positive influences on both house prices and assessed values.

\section{CONCLUSION}

This study employed data from the suburb of Walmer, Nelson Mandela Bay, to investigate the effectiveness of using assessed values as proxies for actual sales prices in a hedonic price framework. In order to do this, a SUR model was estimated and was used to build test statistics in order to compare estimated parameters in the actual sales price equation and the assessed value equation.

The results of this study rejected the hypothesis that the coefficient estimates for house characteristics generated by a hedonic price model using assessed values as the dependent variable are similar to those estimated using the actual sales price as the dependent variable. In addition to this, clear differences exist between the distributions of actual sales prices and assessed values, with actual sales prices values being, on average, lower than assessed values. This does not necessarily imply that they are different in an economically relevant manner (which would be of interest to policy makers). However, although there are clear data advantages to using assessed values as the dependent variable, actual sales prices reflect true market conditions more accurately than assessed values. Economic intuition, thus, suggests that actual sales prices are preferred to assessed values. This should act as a caution to hedonic practitioners that the use of assessed values as the dependent variable should be avoided if actual transaction data is available. 


\section{LIST OF REFERENCES}

Bowman, T. Thompson, J. \& Colletti, J. (2009). Valuation of open space and conservation features in residential subdivisions. Journal of Environmental Management, 90:321-330.

Cameron, A.C. \& Trivedi, P.K. (2005). Microeconometrics: methods and applications. New York: Cambridge University Press.

Cho, S.H., Bowker, J.M. \& Park, W.M. (2006). Measuring the contribution of water and green space amenities to housing values: an application and comparison of spatially weighted hedonic models. Journal of Agricultural and Resource Economics, 31 (3):485-407.

Cotteleer, G. \& Van Kooten. G. C. (2012). Expert opinion versus actual transaction evidence in the valuation of non-market amenities. Economic Modelling, 29(1):32-40.

Damore, D.F. \& Nocholson, S.P. (2014). Mobilizing interests: group participation and competition in direct democracy elections. Journal of Political Behaviour, 36(3):535-552

Darling, A.H. (1973). Measuring benefits generated by urban water parks. Land Economics, 49(1):2234.

Doss, C. R. \& Taff, S.J. (1996). The influence of wetland type and wetland proximity on residential property values. Journal of Agricultural and Resource Economics, 21(1):120-129.

Fink, A. (2003). The Survey Handbook. California: Sage Publications.

Freeman, A. M. (2003). The measurement of environmental and resource values: theories and methods. Washington, D.C.: Resources for the Future.

Greene, W.H. (2011). Econometric analysis, th $E d$. New Jersey: Prentice Hall

http://mlsc.lboro.ac.uk/resources/statistics/Pairedttest.pdf. (Accessed: 24 July 2012).

http://www.nhfc.co.za/files/Social_Housing_Policy_May_2005.pdf. (Accessed: 18 February 2010).

Keller, G. (2011). Statistics for management and economics. Mason, Ohio: South-Western.

Kiel, K.A. \& Zabel, J. E. (1999). The accuracy of owner-provided house values: the $1978-1991$ American housing survey. Real Estate Economics, 27 (2): 263 - 298.

Lee, S.W., Taylor, P.D. \& Hong, S.K. (2008). Moderating effect of forest cover on the effect of proximity to chemical facilities on property values. Landscape and Urban Planning, 86:171-176.

Leggett, C.G. \& Bockstael, N.E. (2000). Evidence of the effects of water quality on residential land prices. Journal of Environmental Economics and Management, 39(2):121-144.

Ma, S. \& Swinton, S.M. (2012). Hedonic valuation of farmland using sale prices versus appraised values. Land Economics, 88(1):1-15.

Nicholls, S. \& Crompton, J.L. (2007). The impact of a golf course on residential property values. Journal of Sport Management, 21(4):555-570.

Rosen, S. (1974). Hedonic prices and implicit markets: product differentiation in pure competition. Journal of Political Economy, $82(1): 34-55$. 
Shier, R. (2004). Statistics: 1.1 Paired t-tests. Mathematics Learning Support Centre.

Sirmans, S.G., Macpherson, D.A. \& Zietz, E.N. (2005). The composition of hedonic pricing models. Journal of Real Estate Literature, 13(1):1-44.

Social Housing Policy for South Africa. (2005). Social Housing Policy for South Africa. South Africa: National Housing Finance Corporation.

South African Property Transfer Guide. (2011). South African Property Transfer Guide.

http://www.saptg.co.za. (Date accessed: 9 February 2011).

Studenmund, A.H. (2006). Using econometrics: $5^{\text {th }} \varepsilon d$. Boston: Addison Wesley.

Weyers, R. (2011). Personal communication. Port Elizabeth: Valuations, Nelson Mandela Bay Municipality. 